\title{
SECRETOS PARA UN HOGAR FELIZ
}

Montero Guerrero, Rubén

Facultad de Teología

Universidad Peruana Unión rubenm32@yahoo.com

Texto base: Lucas 1:5-15

Propósito General: Doctrinal

Palabra clave: Secretos

\section{Introducción}

- Saludo: Es un gran privilegio estudiar la Palabra de Dios, ella es la fuente de toda doctrina verdadera, y manantial inagotable de sabiduría y orientación para cada aspecto de nuestra vida. Hoy la abriremos para aprender a tener un hogar cada día más feliz.

- Frase alusiva: La Biblia nos enseña que Dios estableció el matrimonio. Si el matrimonio es una maravillosa idea que nació en el corazón de Dios, entonces solo el Señor puede mostrarnos cómo tener un hogar feliz. Nuestro Dios, el gran terapeuta familiar de todos los tiempos, ha revelado en su Palabra los principios eternos de la felicidad en la vida familiar. Hoy examinaremos los "Secre- 
tos para un Hogar Feliz" que presenta la eterna y siempre sabia Palabra de Dios.

- Disparador: Una señorita soltera y muy soñadora suspiraba por conocer a su príncipe azul. Le gustaban mucho las historias de amor y vivía en un mundo de ensoñaciones. "¿Cuándo se presentará aquel hombre de personalidad arrolladora que conquistará mi corazón?" se preguntaba. Después de algún tiempo se sentía desilusionada porque el príncipe azul no se dignaba a aparecer por ningún lado. Le habían dicho que para que el príncipe aparezca primero debía besar muchos sapos. Pero la idea de andar besando sapos no le parecía atractiva. Un día llegó una amiga casada, y esta joven, queriendo tener algún sabio consejo, empieza a tocar el tema de los relacionamientos exclamando con un suspiro: "iQué difícil es encontrar un buen marido!". La señora casada, con un suspiro mayor, le dice compasiva: "Querida, eso no es nada, más difícil es conservarlo". Las dos se dieron un gran abrazo consolándose sinceramente una a la otra. Estas mujeres, sin querer, nos dan un gran mensaje: "No importa cuán difícil sea encontrar la persona idónea, mantener el matrimonio es todavía un desafío mayor". Vivimos en una época de creciente escepticismo sobre la posibilidad de formar hogares verdaderamente felices. La historia de Zacarías y Elizabeth es una demostración que es posible tener un hogar verdaderamente feliz.

- Texto: Lucas 1:5-15. Leamos con reverencia la Palabra de Dios.

1. El hogar de Zacarías y Elizabeth constituye un excelente ejemplo de lo que es un hogar cristia- 
no. La Biblia realiza una hermosa descripción de ese hogar: "Ambos eran justos delante del Señor y andaban irreprensibles en todos los mandamientos y ordenanzas del Señor”. ¡Qué maravillosa descripción de un hogar cristiano!

2. La Biblia remarca el hecho que es fundamental tener una base espiritual sólida para poder formar un hogar feliz. Un hogar no crecerá espiritualmente más de lo que cada cónyuge pueda crecer en su propia experiencia espiritual. El hecho que Zacarías y Elizabeth sean considerados "justos delante del Señor” es un poderoso indicativo de una intensa vida de comunión con Dios, porque nadie puede alcanzar la justicia fuera de Dios. Así como se dice de Abraham que creyó a Dios y le fue contado por justicia (Santiago 2:23), se puede deducir que Zacarías e Elizabeth creyeron y su fe también fue contada por justicia.

3. La justificación es apenas el primer paso, es solo el inicio de una vida de obediencia por fe. La vida cristiana no está brevemente limitada a la experiencia de la justificación. Después de la maravillosa realidad de ser declarado justos y de haber sido plenamente perdonados, empieza el camino de la vida con Cristo. El propósito de esta travesía es asemejarnos a Jesús. Esta travesía es conocida también como proceso de la santificación. Caminar diariamente con Dios también era una hermosa realidad en la vida de Zacarías y Elizabeth. El evangelista Lucas describe que ambos eran irreprensibles y andaban en "todos los mandamientos y ordenanzas del Señor".

- Ilustración: Dos pastores estaban conversando sobre los tiempos difíciles que enfrenta la familia. Uno de ellos decía amargamente: "Ya tengo mie- 
do de celebrar matrimonios. He casado muchas parejas y siempre hay una linda ceremonia, todos los novios repiten que se aman y que su unión será para siempre. Luego, de un tiempo se están separando y uno queda mal, parece que todo fue tan solo una comedia." El otro pastor se mostraba de acuerdo con su colega, y con cierta desilusión decía en tono sombrío: "Es verdad, creo que mejor voy a especializarme en funerales, así por lo menos estaré seguro que la ceremonia será para siempre". No hay duda que la institución matrimonial está atravesando una de las mayores crisis de su historia. Tristemente esta realidad también está dentro de nuestra propia iglesia.

- Proposición: En este mensaje deseo compartir los secretos de Zacarías y Elizabeth para tener un hogar verdaderamente feliz.

- Preguntas de transición: ¿Será que es posible tener un matrimonio feliz en este planeta donde el pecado gobierna? ¿Cuáles son los factores que impiden la felicidad en el hogar? ¿Cómo podemos derrotarlos para que nos impidan la felicidad?

\section{Factores que impiden la felicidad en el hogar (Lucas 1:5,7)}

A. Lección: En Lucas 1:5 se habla de Herodes. Este es el llamado Herodes el Grande, aunque a decir verdad no tenía nada de grande ya que era un gobernante títere de los romanos. Este es el mismo Herodes que ordena la muerte de los niños menores de dos años para tratar de matar al que sería el nuevo rey de los judíos.

B. Texto prueba: Mateo 2:16 "Herodes entonces, 
cuando se vio burlado por los magos, se enojó mucho, y mandó matar a todos los niños menores de dos años que había en Belén y en todos sus alrededores, conforme al tiempo que había inquirido de los magos".

a) Herodes atentó, instigado por el propio Satanás, contra la familia. Con un infame decreto, trató de preservar su poder político asesinando a los más inocentes entre los inocentes. Las familias fueron atacadas entre sus miembros más indefensos.

b) Este Herodes era apenas un instrumento en las manos de Satanás. Herodes murió hace dos mil años, pero Satanás ha levantado nuevos Herodes con los que intenta destruir a las familias de hoy, y especialmente a las familias que tienen a Jesús como su fundamento, las familias cristianas.

c) Herodes representa a los enemigos externos de la familia, aquellos peligros que no nacen del seno familiar. Hoy existen formidables enemigos externos que son instrumentos del enemigo para destruir la familia: a) Una sociedad permisiva y contraria a todo valor moral absoluto, b) Medios de comunicación masiva que introducen en nuestros hogares una ética antibíblica, c) Las crisis económicas que provocan angustia en no pocas familias, y tantos otros peligros.

d) Lucas 1:7 Nos muestra que en la vida de Zacarías y Elizabeth había una sombra terrible. Ellos estaban firmes contra los peligros externos, contra las corrientes morales impías de la 
sociedad de su tiempo. Su fe era sólida, pero había una dolorosa realidad que era parte de su vida diaria: Ellos no podían tener hijos. Ese era un peligro que se había incubado dentro de su propio hogar y constituía una amenaza real para su felicidad.

e) Sin embargo, las crisis externas, por muy peligrosas que sean para la felicidad de la familia, están lejos de ser las únicas armas de destrucción familiar en el infame arsenal del enemigo. También existen peligros internos, muchos de estos actúan de un modo silencioso e imperceptible pero son dueños de un gran poder corrosivo, que muchas veces termina destruyendo la estructura de una familia. Algunos de estos peligros son: a) la falta de comunicación en la familia, b) ausencia de un compromiso real, c) la falta de madurez, d) las heridas emocionales no curadas, e) la falta de una vida espiritual saludable en la familia, etc.

C. Cita: Elena de White declara cómo cada día debemos estar atentos para vencer los peligros que nos rodean: "Antes de salir de la casa para ir a trabajar, toda la familia debe ser convocada y el padre, o la madre en ausencia del padre, debe rogar con fervor a Dios que los guarde durante el día. Acudid con humildad, con un corazón lleno de ternura, presintiendo las tentaciones y peligros que os acechan a vosotros y a vuestros hijos, y por la fe atad a estos últimos al altar, solicitando para ellos el cuidado del Señor. Los ángeles ministradores guardarán a los niños así dedicados a Dios”. Conducción del Niño, 491.

D.Ilustración: Imaginemos que un hombre toca la 
puerta de tu casa. Abres la puerta y te llevas un tremendo susto, porque aparece un sujeto que tiene la apariencia de un delincuente: una feísima cicatriz surca su rostro, un peinado que parece el producto de un fenomenal choque eléctrico, la ropa sucia y vieja está hecha jirones, y los zapatos dejando sobresalir el dedo gordo de cada pie. Sin embargo, este hombre trata de parecer amable, te muestra una sonrisa desdentada, y te dice: "no se asuste, solo vine a jugar con sus hijitos". ¿Llamarías a tus hijos para que jueguen con ese desconocido? Por supuesto que yo no lo haría. Los padres tenemos la responsabilidad de proteger a nuestra familia. Sin embargo, los peligros que enfrentan las familias de nuestro tiempo no suelen ser tan evidentes.

E. Aplicación: Si queremos tener una familia feliz debemos estar atentos a los peligros que acechan y que atentan contra la armonía familiar. ¿Qué peligros externos están influyendo negativamente en tu familia? ¿Qué peligros internos están destruyendo la paz de tu hogar? ¿Estás dispuesto a dar tu vida por tu familia? ¿Qué tal si empiezas por enfrentar esos peligros pequeños pero insidiosos que pueden destruir tu hogar?

a) Los peligros externos deben ser enfrentados. Las tempestades pueden venir y tratar de hundir el barco de tu vida. Confía en el poderoso Jesús, pídele que el sea el capitán de tu embarcación.

b) Los peligros internos son más difíciles de enfrentar, porque se tiene que cambiar actitudes, hábitos, y luchar contra nuestras propias emociones y temperamento. Pero nada hay imposi- 
ble para Dios, él puede transformar tu corazón y reconstruir tu hogar aun de las propias cenizas del desamor y la quiebra emocional.

\section{Los secretos para tener un hogar feliz (Lucas 1:8-15)}

A. Lección: La felicidad en la familia nunca llega como resultado de la inercia. Hay que aprender a ser proactivos. La felicidad solo alcanza a quienes están dispuestos a encontrarla. Si no eres feliz en tu vida familiar es porque no has buscado la felicidad, o la has buscado en el lugar equivocado. Tristemente, millones de personas buscan la felicidad en el lugar equivocado.

B. Texto prueba: Salmos 1:1 "Bienaventurado el varón que no anduvo en consejo de malos, $\mathrm{Ni}$ estuvo en camino de pecadores, $\mathrm{Ni}$ en silla de escarnecedores se ha sentado".

a) Este texto es el manual más pequeño del mundo. Es el manual de lo que no es la felicidad. Parafraseando el versículo podríamos repetirlo así: "No encontrarás la felicidad si sigues malos consejos, o si sigues el camino de los pecadores, o si frecuentas a los burladores".

b) Si quieres realizar un viaje hacia Arequipa no debes tomar la panamericana norte. Por más que la autopista te parezca mejor, o más segura, nunca llegarás a Arequipa yendo hacia el norte. Así también, nunca encontrarás la felicidad si la buscas donde ella no está.

C. Ilustración: Dos hombres estaban caminando en la selva. El que iba adelante era el guía, conocía 
bien el camino. El hombre que iba atrás era un forastero, la selva era desconocida para él, pero este hombre iba confiado, sabía que su guía conocía perfectamente el camino. Ya habían caminado varias horas y la noche estaba llegando. El hombre que seguía al guía de pronto lo vio como si estuviese dudando. El guía miraba de un lado a otro. "Será que se ha perdido?" se preguntó el forastero. Lo vio avanzar unos metros y él lo siguió. Otra vez le parecía que estaba dudando. La perspectiva de quedarse a dormir en la selva le parecía intimidante. Le pregunta, "Estás perdido?". El guía le responde con voz serena: "Yo nunca me pierdo en la selva, la conozco como la palma de mi mano". El hombre insiste "iEstás seguro que no has perdido el camino?". El guía se detiene, mira al otro hombre con una mirada profunda y le dice: "En la selva no hay caminos, el camino soy yo".

D.Definición: En la selva de esta vida, el único camino es Cristo. No hay otro camino hacia la felicidad, la paz y la verdadera realización personal. Un hogar no puede alcanzar la felicidad si no es recorriendo el camino a la felicidad. Ese camino es Cristo. Zacarías y Elizabeth entendieron esa gran verdad, y colocaron como prioridad de su vida mantener una íntima relación con Cristo, y una obediencia fiel a los principios expresados en la Palabra de Dios.

a) Lucas 1:8 presenta a un Zacarías que no se desanima a pesar del triste problema que había en su hogar. A pesar que la gente de su tiempo consideraba una maldición no tener hijos, a pesar del paso de los años, y a pesar de la tentación de sentirse abandonado por Dios; 
Zacarías continúa ejerciendo el sacerdocio con fidelidad. Los hombres somos llamados a ser los sacerdotes de la familia, hagamos como Zacarías, nunca renunciemos a ese privilegio. No podemos ser sacerdotes en el templo si antes no lo somos en nuestra propia casa. Vivir nuestro cristianismo en la intimidad de nuestro hogar, es fundamental para la felicidad en la familia.

b) Lucas 1:9 presenta otro aspecto interesante de la historia de Zacarías: él entró en el Santuario del Señor. Zacarías se mantenía en la presencia de Dios. Sabía que la solución a sus dificultades solo estaba en las manos de Dios. No interrumpía su servicio a Dios en el Santuario. No renunciaba a la congregación, ni se desanimaba en su liderazgo en el templo. Estaba firme, porque había dejado toda su ansiedad sobre Dios. La iglesia es un poderoso aliciente para la armonía en la familia.

c) Lucas 1:9 también refiere que Zacarías ofrece el incienso. El incienso representa las oraciones. La vida de Zacarías era una vida ejemplar de oración. Elizabeth también tenía una vida espiritual llena de significado. Ellos colocaron su sufrimiento en las manos de Dios. La falta de la vida que dan los hijos en la familia era un motivo especial de oración. Por eso la Biblia dice que cuando el ángel se presentó, le dijo a Zacarías: "Tu oración ha sido oída y Elizabeth tu mujer tendrá un hijo". Zacarías había aprendido a orar específicamente por los problemas de su familia.

d) Lucas 1:10 dice que cuando Zacarías entró en la presencia de Dios, la multitud quedó afue- 
ra. Una lección importante es que solo Dios puede interferir en la intimidad de un hogar, la multitud debe quedar afuera. La multitud representa los diversos intereses y ocupaciones que destruyen el tiempo y las energías que deberíamos emplear en nuestro relacionamiento familiar. Debemos darle a nuestra familia el lugar que ella merece. Honrar a nuestro cónyuge, amar a nuestros hijos debe ser, después de nuestra intimidad con Cristo, nuestra primera prioridad.

e) El resultado de esas disciplinas que Zacarías cultivó en su vida espiritual y familiar, fue que una nueva vida llegó a su hogar, ellos tendrían un hijo que alegraría sus vidas. Esta pareja de esposos fieles tendrían todavía mayores motivos de alegría, porque el destino de este hijo sería glorioso, sería el profeta que señalaría personalmente quién era el Mesías prometido. Zacarías y Elizabeth alcanzaron nuevas alturas de felicidad porque no desistieron de Dios, porque estuvieron dispuestos a colocar una sólida base espiritual a su familia. Para ellos era real la enseñanza bíblica: "Si Jehová no edifica la casa, en vano trabajan los edificadores" (Salmos 127:1)

E. Cita: Elena de White declara: "Solo la presencia de Cristo puede hacer felices a hombres y mujeres. Cristo puede transformar todas las aguas comunes de la vida en vino celestial. El hogar viene a ser entonces un Edén de bienaventuranza; la familia, un hermoso símbolo de la familia celestial". El hogar cristiano, 24.

a) El secreto de la felicidad matrimonial es la presencia del Señor Jesucristo en la vida de cada miembro de la familia. 
b) La mayor preocupación de los esposos cristianos no debe ser si falta romanticismo, o si es necesario una segunda luna de miel, o si es necesario acudir a un terapeuta. La mayor preocupación debe ser mantener la presencia de Cristo en el hogar, solo así regresarán el romanticismo y la alegría del matrimonio.

\section{Conclusión}

- Resumen: Hemos considerado el hogar de Elizabeth y Zacarías. Un hogar como el de cualquiera de nosotros. Dos fieles hijos de Dios con sus desafíos y sus luchas, pero que aprendieron a colocar un sólido fundamento espiritual a su vida matrimonial, y Dios los bendijo mucho más allá de lo que ellos soñaron.

- Aplicación: Tengamos una preocupación activa por el fundamento espiritual en nuestro hogar. Vivir plenamente nuestro cristianismo es el primer y más decisivo paso en la construcción de un hogar feliz.

- Llamado: Apreciados hermanos y hermanas, permitamos que Cristo haga las transformaciones necesarias en nuestra vida para tener un hogar feliz. ¿Hay alguien que quiere decir a Jesús "te abro las puertas de mi corazón, y también las puertas de mi hogar"? ¿Hay alguien que quiere decirle "Senor mora siempre en mi hogar"? Si hay alguien que quiere tomar esa linda decisión póngase en pie ahora mismo y vamos a orar al Señor.

\section{- Oración Final:}

